\title{
长白山腹地副热带高压后部切变暴雨预报方法研究
}

\author{
零磊 刘娜 \\ 吉林省白山市气象局 \\ DOI:10.32629/eep.v3i6.846
}

\begin{abstract}
[摘要] 本文采用1981年至2015年暴雨天气个例,通过分析历史天气图,找出暴雨天气过程影响系统,对 所有暴雨天气过程按高空影响系统进行分类,统计受带高压后部切变线产生降水的天气过程。给出暴雨 预报指标和数值模式预报指标和相关实况形势场及物理量场数据; 建立暴雨天气过程多元回归预报方 程,并对预报结果进行检验。
\end{abstract}

[关键词] 暴雨; 副热带高压; 急流

\section{1 副热带高压后部切变暴雨个 例库}

统计白山市1981年至2015年08时至 08时24小时暴雨天气个例, 白山市辖区 五个县市分别为临江市、靖宇县、长白 县、抚松县、浑江区。暴雨天气过程定 义为 2 个站以上出现日降水量 $\geqslant 50 \mathrm{~mm}$ 定 义为暴雨日。通过收集统计 1981年到 2015年副高后部切变类暴雨16例。从降 水时间来看, 副高后部切变类暴雨是我 市暴雨的主要天气系统, 主要发生在7月 份至 8 月份均有, 集中时间段为 7 月下旬 到八月上旬, 其中7月 30 日或31日白山出 现暴雨日数较多。

\section{2 副高边缘切变类暴雨的综合 特征}

统计 34 年历史天气图, 副高边缘切 变类暴雨共有 16 例, 合成分析得出概念 模型主要有以下特点:

(1) 我市副高边缘切变降水型状主 要有两种类型, 一类是副热带高压呈 带状分布,一类是副热带高压呈块状 分布。块状副高对应急流和切变线走 向一般经向度较大, 南北一般在 $10 \mathrm{~N}^{\circ}$ 左右; 带状副高对应急流一般东西跨 度较大, 一般在 $10 \mathrm{E}^{\circ}$ 左右。急流风速 大小在 $22 \mathrm{~m} / \mathrm{s}-16 \mathrm{~m} / \mathrm{s}$ 之间。降水主要发 生在急流轴附近, 暴雨区一般在急流 和切变线过境区域和急流轴风速辐合 区域内部。

(2) 此类暴雨天气过程各个物理量
情况, 850hpa 比湿阈值范围为 (10 至 19) $\mathrm{g} * \mathrm{~kg}-1,700 \mathrm{hpa}$ 垂直速度阈值范围为 - (2.2至5.6) $\mathrm{pa} *_{\mathrm{s}}-1$, KI指数阈值范围为 $(32 \text { 至 } 43)^{\circ} \mathrm{C} 、 850 \mathrm{hpa}$ 假相当位温 $(\theta \mathrm{se})$ 阈值范围为 $(70$ 至 85$){ }^{\circ} \mathrm{C} 、 850 \mathrm{hpa}$ 急流阈 值范围为 $(14$ 至 20$) \mathrm{m} / \mathrm{s}$ 。

(3) 检验T639数值预报产品情况结 果显示: 四次副高边缘切变类暴雨天 气过程中物理量预报场均比实况场数 值预报偏大。850hpa比湿偏大 3 个单位 左右, 700hpa垂直速度偏 2 个单位左 右, KI指数偏大 5 个单位、 $850 \mathrm{hpa}$ 假相 当位温 $(\theta \mathrm{se})$ 偏大 7 个单位左 右, $850 \mathrm{hpa}$ 急流偏大 2 个单位左右。整 体预报场存在系统偏大误差, 在实际 预报中可向小订正。

\section{3 副高后部切变类暴雨多元回} 归方程

副高后部切变类暴雨天气均为 7 月下旬和 8 月上旬较多, 副高第三次北 跳和回落时容易触发暴雨, 此类暴雨 一般为混合性质暴雨, 对流性降水占 主导地位, 此类暴雨预报关键是确定 切变线位置以及降水过程中热力条件 分布情况。其中切变线位置和维持时 间以及是否与急流配合等均对暴雨强 度和落区有一定的影响, 本文选取 16 例副高后部切变类暴雨天气进行研 究。本文采用湿度条件选取 850hpa比 湿 q; 动力条件选取 700hpa垂直速度 (Omega)、850hpa急流; 能量条件选取
KI指数、 $850 \mathrm{hpa}$ 假相当位温 $(\theta$ se) 等 物理量。建立实况各物理量与实况降 水量多元线性回归方程。

\begin{tabular}{|c|c|c|}
\hline 回归系数 & 回归系数估计值 & 回归系数置信区间 \\
\hline$X 0$ & -22.4448 & {$\left[\begin{array}{ll}-53.0838 & 8.1941\end{array}\right]$} \\
\hline$X 1$ & -0.3366 & {$\left[\begin{array}{ll}-1.3301 & 0.6570\end{array}\right]$} \\
\hline$X 2$ & 0.5182 & {$\left[\begin{array}{ll}-2.9896 & 4.0260\end{array}\right]$} \\
\hline$X 3$ & 0.6048 & {$\left[\begin{array}{ll}-0.5833 & 1.7929\end{array}\right]$} \\
\hline$X 4$ & -0.1199 & {$\left[\begin{array}{ll}-0.6025 & 0.3627\end{array}\right]$} \\
\hline$X 5$ & 0.4617 & {$\left[\begin{array}{ll}-0.1512 & 1.0745\end{array}\right]$} \\
\hline 1. $R^{2}=0.6615 \mathrm{~F}=5.4278 \mathrm{P}<0.001 \mathrm{~S}^{2}=5.8070$ \\
\hline
\end{tabular}

副高后部切变类暴雨预报多元线性 回归方程:

$\mathrm{Y}=-22.4448-0.3366 \times 1+0.5182 \times 2+0$ . 6048x3-0. 1199x4+0.4617×5 (方程1)

预报模型试用范围: 副高后部切变 类引起的暴雨, 暴雨天气型符合上述的 副高后部切变类暴雨模型。

4 副高后部切变类暴雨多元回 归方程检验

预报模型的检验情况: 将近年来 2013年 7月 19 日和 8 月 17 日两次暴雨天 气过程物理量产品带入预报模型得出 24小时总降水量, 再插值到本地站点 上进行检验, 结果显示模式预报存在 系统误差, 预报量均比实况降水大, 量 级在 10 至 $20 \mathrm{~mm}$ 之间, 暴雨预报落区基 本正确。

\section{5 小结}



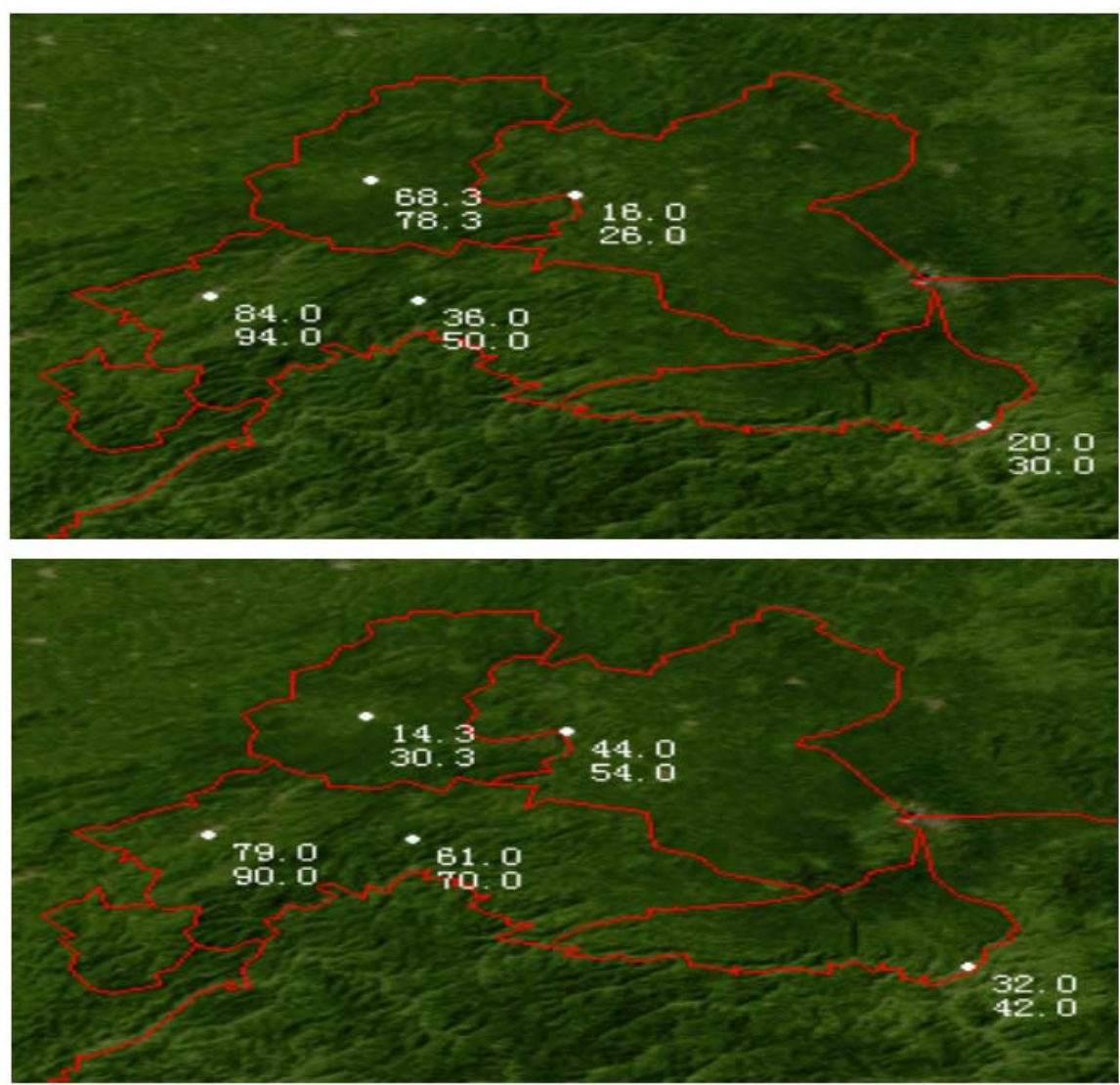

图 62013 年 7 月 19 日和 8 月 17 日 24 小时实况场和预报场降水量检验

(1) 我市副热带高压后部切变降水 型状主要有两种类型, 一类是副热带高 压呈带状分布,一类是副热带高压呈块 状分布。

(2) 块状副高对应急流和切变线走 向一般经向度较大, 南北一般在 $10 \mathrm{~N}^{\circ}$ 左右; 带状副高对应急流一般东西跨
19) $g * k g-1,700 h p a$ 垂直速度阈值范围为 - (2.2至5.6) pa*s -1 , KI 指数阈值范围为 $(32 \text { 至 } 43)^{\circ} \mathrm{C} 、 850 \mathrm{hpa}$ 假相当位温 $(\theta \mathrm{se})$ 阈值范围为 $(70 \text { 至 } 85)^{\circ} \mathrm{C} 、 850 \mathrm{hpa}$ 急流阈 值范围为 $(14 \text { 至 } 20)^{\circ} \mathrm{C}$ 。

(4) 检验 T639数值预报产品情况结 果显示: 四次副高后部切变类暴雨天气 过程中物理量预报场均比实况场数值预 报偏大。 $850 \mathrm{hpa}$ 比湿偏大 3 个单位左 右, $700 \mathrm{hpa}$ 垂直速度偏 2 个单位左右, KI 指数偏大 5 个单位、 $850 \mathrm{hpa}$ 假相当位温 $(\theta \mathrm{se})$ 偏大 7 个单位左右, $850 \mathrm{hpa}$ 急流偏 大 2 个单位左右。整体预报场存在系统偏 大误差, 在实际预报中可向小订正。

(5)副高后部切变类暴雨预报误差 在 10 至 $20 \mathrm{~mm}$ 之间。总体来说预报方程 预报量级略大, 在实际工作中可向小 量级方向订正。实际预报工作中确定 形势场后, 再将数值产品物理量数值 经过修正后带入模式方程进行降水定 量预报。

\section{[参考文献]}

[1]孙力,安刚.1998年松嫩流域东 北冷涡大暴雨过程的诊断分析 [J]. 大气 科学,2001,25(3):342-354.

[2]刘实,朱其文.1995年吉林省异常 旱涝的影响因子分析 [J]. 吉林气 象,1996,(1):11-13.

[3]丁士戬.吉林省大暴雨的统计分 析[J].大气科学, 1983,7(4):432-437. 